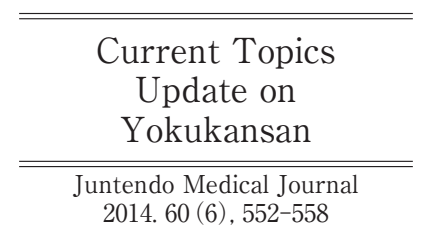

\title{
The Latest Clinical Findings for Yokukansan Based on Its Pharmacological Effects: Yokukansan Update
}

\author{
RIKA TSUKADA*, MASAKO ISEKI* \\ * Department of Anesthesiology and Pain Management, Juntendo University Faculty of Medicine, Tokyo, Japan
}

\begin{abstract}
Yokukansan is a formulation containing 15\% Uncariae Uncis Cum Ramulus, 10\% Bupleuri Radix, 15\% Cnidii Rhizoma, 15\% Angelicae Radix, 20\% Atractylodis Lanceae Rhizoma, 20\% Poria and 7\% Glycyrrhizae Radix. In addition to its well-established actions on serotonin and glutamate nerve systems, various other effects including suppression of nerve cell excitation, dose-dependent control of brain cell degeneration and protection of nerve sheaths have gradually been elucidated, among which its effectiveness on neuropathic pain has also been evidenced in basic research. In recent years, its wide spectrum of efficacy has given rise to increased use for neuropathic pain along with more conventional applications, such as for treating children's night cry and symptoms of dementia. Although yokukansan is an easy-to-use formulation, even for elderly patients, care must be taken for the complication of hypokalemia.
\end{abstract}

Key words: yokukansan, neuropathic pain

\section{Introduction}

Yokukansan (抑肝散) is a traditional Japanese medicine (kampo medicine- 漢方) that has long been widely used in Japan due to being "effective against sleeplessness, irritability and the tendency to easily become angry, which are caused by nervousness and lack of power in the abdomen, and was originally used against night crying, agitation and sleeplessness in children." Recently, however, yokukansan has been demonstrated to achieve significant improvements in the domains of psychiatry and pain relief, especially in patients with peripheral symptoms of dementia. Following recent progress in clinical trials and basic research, this formulation is now generally recognized to be a promising drug.

\section{Composition}

Yokukansan is a mixture of seven herbal medicines (Table-1), including 15\% Uncariae Uncis Cum Ramu-
Table-1 The components of yokukansan

Uncariae Uncis Cum Ramulus (釣藤鈎)

Bupleuri Radix (柴胡)

Cnidii Rhizoma (川芦)

Angelicae Radix (当帰)

Poria (伏苓)

Glycyrrhizae Radix (甘草)

Atractylodis Lanceae Rhizoma (蒼术)

lus (釣藤鈎), 10\% Bupleuri Radix (柴胡), 15\% Cnidii Rhizoma (川节), 15\% Angelicae Radix (当帰), 20\% Atractylodis Lanceae Rhizoma (蒼术), 20\% Poria (伏 苓) and 7\% Glycyrrhizae Radix (甘草).

The principal agent of yokukansan is Uncariae Uncis Cum Ramulus, which reduces overexcitement of the liver function (肝気). Bupleuri Radix and Cnidii Rhizoma support this ingredient by harmonizing the flow of energy (qi - 気). Cnidii Rhizoma smoothens the blood flow in conjunction with Angelicae Radix, helping to alleviate pain. Poria and Atractylodis Lanceae Rhizoma harmonize the digestive functions and improve the balance of water in the body. Glycyrrhizae Radix supports these functions and is

Corresponding author: Rika Tsukada

Department of Anesthesiology and Pain Management, Juntendo University Faculty of Medicine

2-1-1 Hongo, Bunkyo-ku,Tokyo 113-8421, Japan

TEL: +81-3-3813-3111 (ext. 5456) E-mail: usagipunch@tiara.ocn.ne.jp

〔Received Nov. 6, 2014〕 


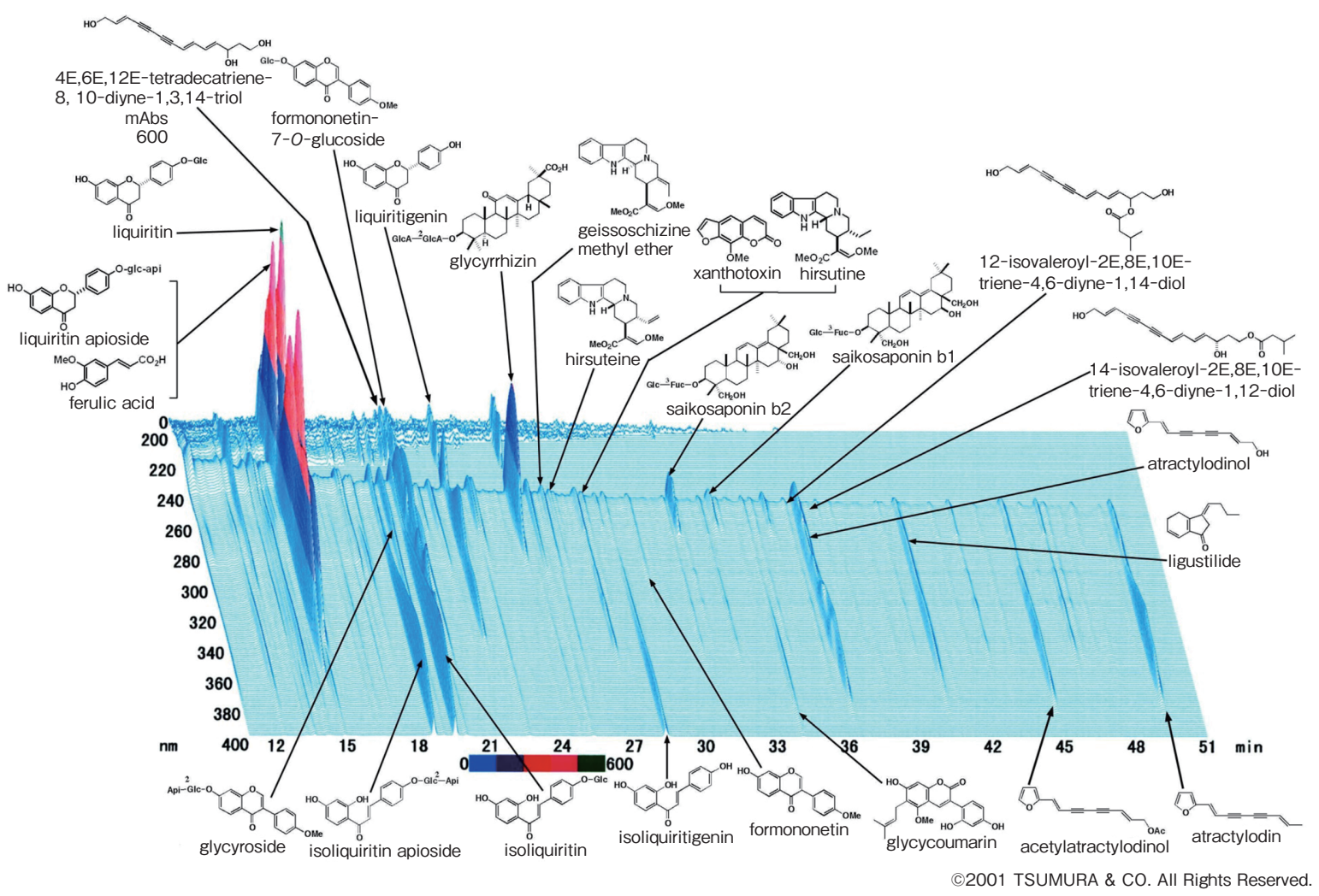

Figure-1 3D HPLC pattern of yokukansan

Table-2 Major components, medicinal properties and indications for each herbal ingredient

\begin{tabular}{|c|c|c|c|}
\hline & Source & $\begin{array}{l}\text { Major ingredients and their medici- } \\
\text { nal properties }\end{array}$ & Indication \\
\hline $\begin{array}{l}\text { Uncariae Uncis Cum } \\
\text { Ramulus (釣藤鈎) }\end{array}$ & $\begin{array}{l}\text { Thorns of Uncaria rhynchophylla } \\
\text { Miquel, Uncaria sinensis Havi- } \\
\text { land or Uncaria macrophylla } \\
\text { Wallich (Family: Rubiaceae) }\end{array}$ & $\begin{array}{l}\text { - Rhynchophylline - dilation of blood } \\
\text { vessels, sedation, laxation of the } \\
\text { alimentary tract, slowing of the } \\
\text { heart rate } \\
\text { - Hirsutine- dilation of blood vessels, } \\
\text { spasmolysis }\end{array}$ & $\begin{array}{l}\text { Convulsion, high fever, spasm, } \\
\text { headache or vertigo in children }\end{array}$ \\
\hline Bupleuri Radix（柴胡） & $\begin{array}{l}\text { Roots of Bupleurum falcatum L. } \\
\text { (Family: Umbelliferae) }\end{array}$ & $\begin{array}{l}\text { - Saikosaponin a: } \mathrm{R}=-\beta-\mathrm{OH} \\
\text { - Saikosaponin d: } \mathrm{R}=-\alpha-\mathrm{OH}-\text { anti- } \\
\text { inflammatory activities, improve- } \\
\text { ment of liver functions }\end{array}$ & $\begin{array}{l}\text { Pain on pressure in the chest- } \\
\text { abdominal or lower side regions, } \\
\text { repeated fever and remission, } \\
\text { depression, restlessness }\end{array}$ \\
\hline Cnidii Rhizoma, (川芦) & $\begin{array}{l}\text { Roots of Cnidium officinale Makino, } \\
\text { generally parboiled (Family: Umbel- } \\
\text { liferae) }\end{array}$ & $\begin{array}{l}\text { - Ligustilide - spasmolysis } \\
\cdot \text { Cnidilide } \\
\cdot \text { Butylidenephthalide }\end{array}$ & $\begin{array}{l}\text { Irregular menstruation, menstrual } \\
\text { cramps, anemia, chill, pains, head- } \\
\text { ache }\end{array}$ \\
\hline Glycyrrhizae Radix（甘草） & $\begin{array}{l}\text { Roots and runners of Glycyrrhiza } \\
\text { uralensis Fischer or Glycyrrhiza } \\
\text { glabra L. (Family: Leguminosae) }\end{array}$ & $\begin{array}{l}\text { Dipotassium glycyrrhizate -peptic } \\
\text { ulcer agent, anti-inflammatory, anti- } \\
\text { tussive, tocolysis, liver protection, } \\
\text { anti-allergy }\end{array}$ & $\begin{array}{l}\text { Abdominal pain, muscle pain, arthri- } \\
\text { tis, peptic ulcer }\end{array}$ \\
\hline Poria（伏苓） & $\begin{array}{l}\text { Sclerotium of Poria cocos Wolf, } \\
\text { generally most of the outer layer is } \\
\text { removed (Family: Polyporacase) }\end{array}$ & $\begin{array}{l}\cdot \text { Ergosterol - precursor to Vitamin } \\
\text { D } \\
\cdot \text { Pachymic acid -anti-inflammation }\end{array}$ & $\begin{array}{l}\text { Edema due to micturition disor- } \\
\text { der, diarrhea, lack of appetite due } \\
\text { to gastric disorders, indigestion, } \\
\text { palpitation, insomnia }\end{array}$ \\
\hline $\begin{array}{l}\text { Atractylodis Lanceae } \\
\text { Rhizoma (蒼术) }\end{array}$ & $\begin{array}{l}\text { Roots of Atractylodes lancea De } \\
\text { Candolle or Atractylodes chinen- } \\
\text { sis Koidzumi (Family: Composi- } \\
\text { tae) }\end{array}$ & $\begin{array}{l}\text { - Hinesol, } \quad \beta \text {-eudesmol -peptic ulcer } \\
\text { agent, CNS depressant, anti-bacterial, } \\
\text { vasopressin-angiotensin II receptor } \\
\text { inhibition }\end{array}$ & $\begin{array}{l}\text { Indigestion, diarrhea, diaphoresis, } \\
\text { ague }\end{array}$ \\
\hline Angelicae Radix (当帰) & $\begin{array}{l}\text { Roots of Angelica acutiloba Kitagawa } \\
\text { or Angelica acutiloba Kitagawa var. } \\
\text { Sugiyamae Hikino, generally par- } \\
\text { boiled (Family: Umbelliferae) }\end{array}$ & $\begin{array}{l}\text { - Ligustilide/Butylidenephthalide - } \\
\text { spasmolysis } \\
\cdot \text { Ferulic acid - antioxidant, anti-agglu- } \\
\text { tination }\end{array}$ & $\begin{array}{l}\text { Women's diseases including irregu- } \\
\text { lar menstruation, menstrual cramps, } \\
\text { abdominal pain, pain, chill and } \\
\text { circulatory deficit }\end{array}$ \\
\hline
\end{tabular}


thought to act as a harmonizer of all ingredients in yokukansan.

Figure -1 and Table -2 list the main ingredients of yokukansan and their currently known medicinal properties. The ingredients of yokukansan synergize as well as countervail each other's effects, ensuring the efficacy of the entire formulation.

\section{Traditional interpretation and clinical application of yokukansan}

Yokukansan was first mentioned in a 20 -volume series of pediatric medical books called "Hoei Satsuyou" published during the Ming (1368-1644) dynasty in China. In Japan, yokukansan was first mentioned in a publication from the "Momijiyama Bunko" library created and maintained by the Tokugawa shogunate ${ }^{1)}$ and remains widely used today.

The "Hoei Satsuyou" mentioned above describes yokukansan as " $\cdots$ treat (ing) symptoms in children, such as convulsions due to kyonetsu (hollow fever) in the passage of the liver, fever and chills associated with clenched teeth or spasms, vomiting of slime, lack of appetite with abdominal bloating and/or being fractious at night.... This formulation should be administered to both the affected child and his/her mother." In summary, yokukansan is used to treat spasms or night cries in scrofulous children.

As the "yokukan" part of the name literally means to control the liver, yokukansan is a formulation for treating an overly increased liver function. Tables -3

Table-3 Functions of the liver

- Controls Sosetsu (疏泄 - similar to metabolism) : Controls emotion, facilitates mental functions, facilitates digestion, maintains qi and blood

- Controls Zoketsu (蔵血- control of blood flow from liver) : Storage of blood, controls the volume of circulated blood

- Controls Kin (筋- muscle) : Facilitates motor functions

- Kaikyo (開竅- make senses clear) of eyes: Improves eyesight

Table-4 Symptoms of liver hyperactivity

- Hyperactivity of the mental function: depression and excitation

- Hyperactivity of the digestive function: indigestion, abdominal pain, sense of fullness in the abdomen, vomit, heart burn

- Hyperactivity of the head function: dizziness, ringing ear, headache, hot flush

- Hyperactivity of the circulatory function: muscle convulsion, paralysis, motor disorders, menstrual disorders and-4 summarize the functions of the liver and symptoms associated with their acceleration.

It should be noted that the term “liver (肝)" is used here as a concept unique to oriental medicine. Tables -3 and -4 present the functions of the liver in the oriental sense and list symptoms associated with their overactivation.

The "kyonetsu (hollow fever) " described in "Hoei Satsuyou" refers to fever believed to be caused by an insufficient blood flow in the liver, which differs from the "fever" that occurs in the general sense and requires pyretolysis. Yokukansan is positioned as a formulation for controlling clinical conditions in patients with aggravated kyonetsu causing neurological symptoms.

While yokukansan is originally a pediatric formulation, it is also widely prescribed to adults. For example, in the "Hoei Satsuyou," yokukansan is prescribed to both the affected child and mother.

In “Saneikan Ryochi Zatsuwa (餐英館療治雑話), ” published in the late Edo period in Japan, MEGURO Dotaku (目黒道玩) states that, “Yokukansan is also effective against partial paralysis in adults. Indicated patients are those who feel Renkyu (攣急 strong muscle tone) on the left side in addition to Renkyu and pulsation along the abdominal middle line starting from the epigastric fossa. The patient feels constriction in the abdomen even though there is no concentration of qi (気 - vital energy) around the epigastric fossa and no firmness can be felt in the abdominal area. If the patient admits to having a tendency to become easily irritated, this formulation will certainly be effective. Yokukansan may also be indicated for insomnia. The diagnosis of insomnia should be based on Fukusho in conjunction with other symptoms. The formulation is particularly effective against insomnia in hot-tempered patients."

Fukusho (腹証 - abdominal conditions) is a diagnostic technique developed in the Edo era and is particular to Japanese Kanpo medicine. Feeling the abdomen of the patient in order to determine his/her Fukusho allows for a suitable prescription to be identified, as described in the above description of yokukansan.

On the other hand, OTSUKA Keisetsu (大塚敬節) indicated that Sho (証 - conditions/observance) for yokukansan include the flaccidness/dysphoria type of Sho in addition to the tension/excitation type described by Dotaku ${ }^{2)}$. 


\section{Pharmaceutical properties of yokukansan}

In recent years, much progress has been made regarding the pharmaceutical properties of yokukansan, resulting in the knowledge described below (Table-5, Figure-2).

\section{Mechanisms of action of yokukansan}

It has been gradually elucidated that yokukansan has several mechanisms of action, including effects on the serotonin (5-hydroxytryptamine: 5 -HT) and glutamate-mediated nervous systems, inhibition of excited nerve cells, dose-dependent suppression of the denaturation of brain cells in thiamine-deficient (TD) rats and protective actions in nerve sheaths.

\section{Effects on the serotonin-mediated nervous system}

A positive correlation has been suggested to exist between depression of the brain serotonin $(5-\mathrm{HT})$ function and hallucinations or aggressive behaviors. Serotonin is a neurotransmitter that participates in the descending inhibitory system, which controls the transmission of pain signals from the brainstem to the spinal cord by suppressing the communication channels for these signals.

Known actions of yokukansan on the serotonin-mediated nervous system include a partial agonistic effect on 5-HT1A receptors that suppresses excitement in the nervous system ${ }^{3)}$ and downregulation of the 5-HT2A receptors involved in excitement of the nervous system ${ }^{4)}$.

\section{Effects on the glutamate-mediated nervous system}

While glutamate controls high-order functions, such as memory, an excessive concentration of this compound in the extracellular fluid is believed to be responsible for cell death associated with certain neurological diseases.

It is estimated that yokukansan suppresses the death of nerve cells by inhibiting an elevation of the glutamate level in the extracellular fluid ${ }^{5)}$.

On the other hand, cells contain a cystine transport system involving glutamate/cystine antiporters (Xc-system) that move extracellular cystine into the cell and intracellular glutamate out of the cell. The cystine captured by this system is used to synthesize glutathione (GSH), which acts as a scavenger of radical oxygen or hydrogen peroxide

Table-5 Mechanisms of action of yokukansan

Serotonin-mediated nervous system

- 5-HT1A partial agonistic activity

-5-HT2A down regulatory activity

Glutamate-mediated nervous system

- release inhibition

- Glutamate transporter activation

- Inhibition of the rise of extracellular glutamate level

- Effects through the glutamate receptors

- Suppression of oxidation stress, enhancement of GSH

(Adapted from: Katsuyoshi MINAKAI: Brain 21, 2009; 12: 400403)

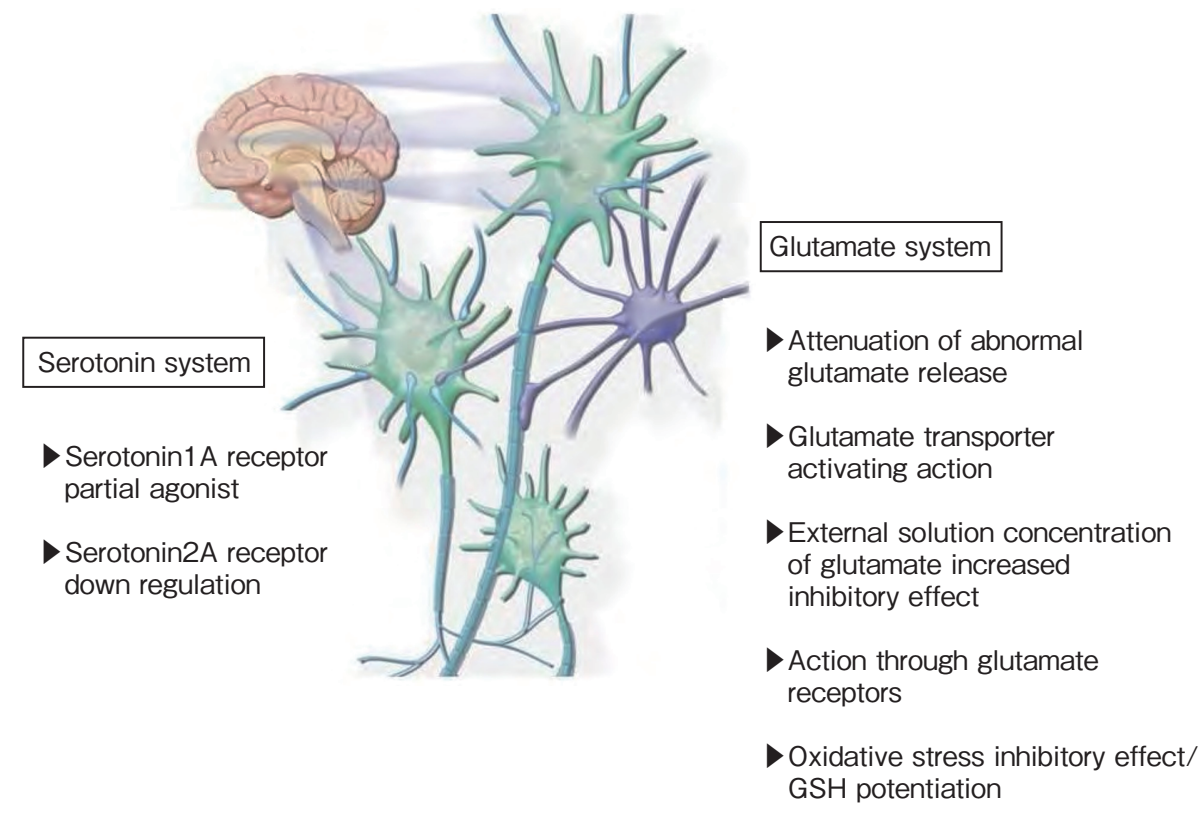

Figure-2 Mechanisms of action of yokukansan 
Table-6 Symptoms of BPSD

\begin{tabular}{ll}
\hline Psychological symp- & $\cdot$ Hallucination (including visual and auditory hallucinations) \\
toms & - Delusion (including delusions of theft, persecution and jealousy) \\
& - Delusions related to sleep disorders (including insomnia and REM sleep behavior \\
& disorder) \\
$\cdot$ & Mood disorders (including depression, mania, anxiety, excitement and apathy) \\
& Personality disorders (including euphoria, disinhibition, tendency to become angry and \\
& lack of interest) \\
\hline Behavioral disorders & $\cdot$ Aggressive behaviors (including violence and verbal abuse), fretfulness, screaming, \\
& rejection \\
$\cdot$ & Inappropriate/purposeless behaviors (including pseudo-work, unclean behavior, wander- \\
& ing and collection) \\
& Eating disorders (including allotriophagy, overeating and refusal to eat) \\
\hline
\end{tabular}

generated by NMDA stimuli or other activities to protect cells from damage due to oxidative stress. In cells exposed to high levels of glutamate, however, overstimulation of NMDA receptors and inhibition of GSH production via the $\mathrm{Xc}$-system induce apoptosis of cells triggered by oxidative stress $^{7)}{ }^{8)}$.

Yokukansan is known to act as an antagonist of NMDA receptors by binding to these receptors ${ }^{9}$ 10) and has been reported to suppress the death of P12 cells triggered by glutamate ${ }^{11)}{ }^{12}$. These findings suggest that the ability of yokukansan to generate $\mathrm{Xc}-\mathrm{GSH}$ directly protects cells.

These effects of yokukansan on the 5-HT and glutamate-mediated nervous systems may provide the basis for its ameliorating effects on the peripheral symptoms of dementia and ability to alleviate pain.

\section{Clinical applications}

In addition to its well-established position in traditional oriental medicine, yokukansan is now widely recognized as a therapeutic agent for neuropsychiatric conditions, including peripheral symptoms of dementia and neuropathic, chronic and/or idiopathic pain.

Improvements with yokukansan treatment have been reported for schizophrenia, borderline personality disorder, peripheral symptoms of Parkinson's disease $^{13)-15)}$, REM sleep behavior disorder ${ }^{16)}$, restless legs syndrome ${ }^{17)}$, Charles Bonnet syndrome with hallucinations as the cardinal symptom ${ }^{18)}$, blepharospasm and delirium after heart or major blood vessel surgery in elderly patients.

\section{Peripheral symptoms of dementia}

In dementia patients, peripheral symptoms, including hallucinations, delusions, depression, delirium, excitement, aggressive behavior and wandering, are observed in addition to major symptoms, such as disturbances in memory or orientation. These peripheral psychoneurotic or behavioral symptoms are generally referred to as BPSD (behavioral and psychological symptoms of dementia) and are summarized in Table-6. BPSD is a major cause of admission to treatment facilities as it results in the deterioration of activities of daily living, which in turn increases the physical and psychological burdens of caregivers. As described above, yokukansan is thought to have ameliorating effects on these symptoms.

While BPSD is generally treated with psychotropic agents, these drugs may be associated with adverse events, including extrapyramidal symptoms, a tendency toward falls or a decrease in ADL's. With a treatment spectrum almost comparable to that of psychotropic agents with comparatively less side effects, yokukansan is now becoming a more important therapy.

\section{Neuropathic pain}

Neuropathic pain is believed to be caused by plastic transformation in the nerve circuit. While there remain many unsolved questions with respect to the mechanisms of nerve plasticity, it is generally accepted that NMDA glutamate receptors are involved.

Suzuki et al. used a rat chronic constriction injury model to demonstrate the anti-allodynic properties of yokukansan and identified the underlying mechanism as involving suppression of the extracel- 


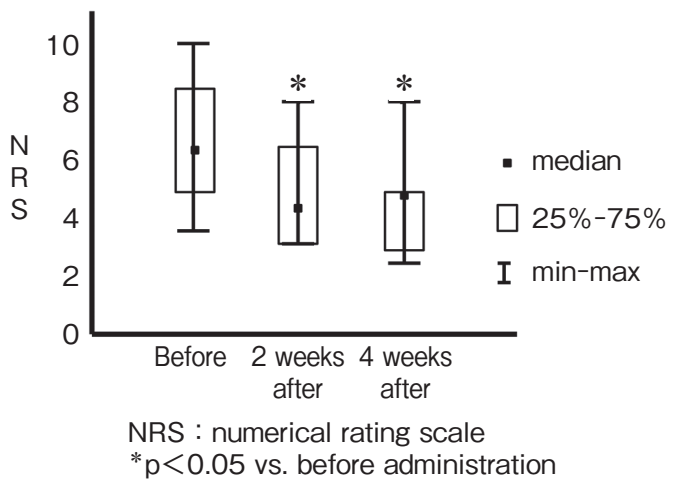

Figure-3 Pain levels before and after yokukansan administration $^{20)}$

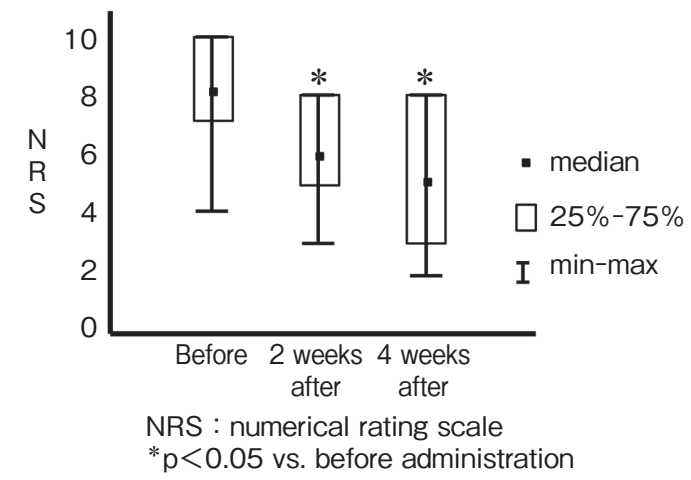

Figure-4 Allodynia levels before and after yokukansan administration $^{20)}$

lular glutamate level via the activation of transporters ${ }^{19)}$.

Sakai et al. also demonstrated that pain and allodynia can be significantly decreased in the setting of postherpetic neuralgia by adding yokukansan to the patient's original drug regimen $(\text { Figure }-3,4)^{20)}$.

\section{Our experience with yokukansan}

Various researchers have reported the effects of yokukansan in alleviating pain ${ }^{21}$, including postoperative analgesia, migraine, fibromyalgia syndrome, chronic perineal pain and complex regional pain syndrome (CRPS). Our clinic also widely uses yokukansan in patients with neuropathic pain as well as mixed pain conditions, such as postherpetic neuralgia, diabetic neuropathy, sciatic neuralgia, numbness or pain associated with chemotherapy and postoperative pain. While therapeutic agents for neuropathic pain are associated with adverse events primarily originating from the central nervous system, such as sleepiness or wobbliness, yokukansan is free of these drawbacks, making it safe to use in elderly subjects. Based on this safety profile, yokukansan is sometimes selected as the first-choice drug for high-risk elderly individuals. yokukansan may also be used when continuing or increasing the dose of therapeutic agents for neuropathic pain is difficult as a result of side effects. Our clinic has also experienced cases in which combining yokukansan with antidepressants, antiepileptic agents or opioids increases the therapeutic effects of treatment.

Since chronic pain is not limited to physical pain, but rather is an overall experience involving both emotional and cognitive aspects, such pain must be evaluated with a holistic view of the patient, including mood, cognition and behavior, in addition to the degree of the pain itself, which is heavily affected by these factors.

Our clinical experience suggests that anger, hostility, distrust or exasperation may aggravate pain in some patients. Sarno has proposed that low back pain may be the result of anger unconsciously accumulated by the patient ${ }^{22}$.

In addition, patient irritability may delay the formulation of positive rapport between the patient and his/her medical staff, interfering with the course of treatment, as when the patient refuses to cooperate with the clinical examination.

Yokukansan, which has been used to treat irritated or excited patients since ancient times, continues to be useful in clinical practice.

\section{Reported side effects of yokukansan}

Although various side effects of yokukansan have been reported, including hypokalemia, digestive symptoms, pseudoaldosteronism, fatigue, increased blood pressure, edema, weight gain, numbness or pain in the limbs, twitches or shaking of the muscles and a sense of physical weakness, yokukansan remains relatively safe, with a lower risk of side effects than other treatments, making it easier to apply in elderly patients.

\section{Conclusion}

This chapter described the characteristics of yoku- 
kansan, which has long been used in Japan. While the traditional herbal (Kanpo - 漢方) medicine brought to Japan from China between the 8th and 16th centuries exhibited significant progress in the Edo period (16031868), it's place as mainstream medicine was superseded by the Western science Rangaku (蘭 学) during the Meiji Restoration (明治維新) when Japan opened the country to the outside world and has since become generally recognized as a form of alternative or supplementary medicine.

In recent years, however, the efficacy of traditional Kanpo medicine has been reexamined based on new knowledge of the structures and fundamental activities of major ingredients. For example, EBM analyses are actively carried out in both clinical and basic research studies. Although many elements of yokukansan are not fully understood, it may be a useful remedy for many ailments, including dementia and chronic pain, both of which have become major sociological issues in Japan in association with increasing longevity and aging of the society.

\section{References}

1) Mayanagi M: Knowledge of Kanpo formulations for hospital pharmacists. J Jpn Soc Hosp Pharm (真柳 誠 : 病院薬凨師のための漢方製凨の知識. 日病薬誌), 1997; 33: 315-316

2) Otsuka K: Otsuka Keisetsu Collection, vol. 7, Tokyo: Shunyodo Publishing (大塚敬節 : 大塚敬節著作集第 7 巻. 東京：春陽堂書店), 1981: 174-185.

3) Terawaki T, Ikarashi Y, Sekiguchi K, Nakai Y, Kase Y: Partial agonistic effect of Yokukansan on human recombinant serotonin $1 \mathrm{~A}$ receptors expressed in the membranes of Chinese hamster ovary cells. J Ethnopharmacol, 2010; 127: 306-312.

4) Egasira N, Iwasaki K, Ishibashi A, et al: Repeated administration of Yokukansan inhibits DOI-induced head-twitch response and decreases expression of 5-hydroxytryptamine (5-HT) 2A receptors in the prefrontal cortex. Prog Neuropsychopharmacol Biol Psychiatry, 2008; 32: 1516-1520.

5) Patralia RS, Wang YX, Niedzielski AS, Wenthold RJ: The metabotropic glutamate receptors, mGluR2 and mGluR3, show unique postsynaptic, presynaptic and glial localizations. Neurosci, 1996; 71: 949-976.

6) Lo M, Wang YZ, Gout PW: The x (c)-cystine/glutamate antiporter: a potential target for therapy of cancer and other disease. J Cell Physiol, 2008; 215: 593-602.

7) Kang TH, Murakami Y, Matsumoto K, et al: Rhynchophylline and isorhynchophylline inhibit NMDA receptors expressed in Xenopus oocytes. Eur J Pharmacol, 2002; 455: 27-34.
8) Lee J, Son D, Lee P, et al: Protective effect of methanol extract of Uncaria rynchophylla against excitotoxicity induced by $\mathrm{N}$-methyl-D-aspartate in rat hippocampus. J Pharmacol Sci, 2003; 92; 70-73.

9) Kawakami Z, Kanno H, Ueki T, et al: Neuroprotective effects of yokukansan, a traditional Japanese medicine, on glutamate-mediated excite-toxicity in cultured cells. Neurosci, 2009; 159: 1397-1407.

10) Edwards MA, Loxley RA, Williams AJ, Connor M, Phillips JK: Lack of functional expression of NMDA receptors in PC12 cells. Neurotoxicol, 2007; 28: 876-885.

11) Takeda $A$, Tamano $H$, Itoh $H$, Oku N: Attenuation of abnormal glutamate release in zinc deficiency by zink and Yokukansan. Neurochem Int, 2008; 53: 230-235.

12) Kawakami Z, Kanno H, Ueki T, et al: Neuroprotective effects of yokukansan, a traditional Japanese medicine, on glutamate-mediated excitotoxicity in cultured cells. Neuroscience, 2009; 159: 1397-1407.

13) Miyaoka T, Furuya M, Yasuda H, et al: Yi-gan san as adjunctive therapy for treatment-resistant schizophrenia: an open-label study. Clin Neuropharmacol, 2009; 32: 6-9.

14) Miyaoka T, Furuya M, Yasuda H, Hayashia M, Inagaki $\mathrm{T}$, Horiguchi J: Yi-gan san for the treatment of borderline personality disorder; an open-label study. Prog Neuropsychopharmacol Biol Psychiatry, 2008; 32: 150-154.

15) Fujioka T, Kawanabe K, Kiyotsuka T, Iguchi H, Iwasaki Y: Efficacy of Yokukansan on the hallucination observed on a Parkinson disease patient being treated with L-DOPA. Neurological Therapeutics (藤岡俊樹, 川邊清一, 清塚鉄人, 井口裕章, 岩崎泰雄 : L - DOPA治療中の PARKINSON 病 患者にみられた幻覚に対する抑肝散の効果. 神経治療学), 2009; 26: 55-59.

16) Shinno H, Kamei M, Nakamura Y, Inami Y, Horiguchi J: Successful treatment with Yi-Gan San for rapid eye movement sleep behavior disorder. Prog Neuropsychopharmacol Biol Psychiatry, 2008; 32: 1749-1751.

17) Shinno H, Yamanaka M, Ishikawa I, et al: Successful treatment of restless legs syndrome with the herbal prescription Yokukansan. Prog Neuropsychopharmacol Biol Psychiatry, 2010; 34: 252-253.

18) Miyaoka T, Furuya M, Kristian L, et al: Yi-gan san for treatment of Charles Bonnet syndrome (visual hallucination due to vision loss): an open-label study. Clin Neuropharmacol, 2011; 34: 24-27.

19) Suzuki Y, Mitsuhata H, Yuzurihara M, Kase Y: Antiallodynic effect of herbal medicine yokukansan on peripheral neuropathy in rats with chronic constriction injury. Evid Based Complement Altemat Med, 2012: 953459.

20) Sakai T, Goto S, Sumikawa K: Analgesic effects of Yokukansan on postherpetic neuralgia. Pain and Kampo Medicine (境 徹也, 後藤志乃, 澄川耕二 : 抑肝散の帯状疮 疹後神経痛に対する鎮痛効果. 痛みと漢方), 2010; 20: 3032.

21) Yoshitaka N, Nakamura Y, Tajima K, Kawagoe I, Kanai $\mathrm{M}$, Mitsuhata H: Efficacy of traditional herbal medicine yokukansan on patients with neuropathic pain. Masui, 2009; 58: 1248-1255.

22) Sarno JE: Healing Back Pain. New York: Warner Books, 1991: 1-59. 